\title{
Reaction Chemistry in the Afterglow of an Oxygen-Helium, Atmospheric-Pressure Plasma
}

\author{
James Y. Jeong, ${ }^{\dagger}$ Jaeyoung Park, ${ }^{\ddagger}$ Ivars Henins, ${ }^{\ddagger}$ Steve E. Babayan, ${ }^{\dagger}$ Vincent J. Tu, ${ }^{\dagger}$ \\ Gary S. Selwyn, Guowen Ding, ${ }^{\dagger}$ and Robert F. Hicks*, \\ Chemical Engineering Department, University of California, Los Angeles, California 90095, and \\ Plasma Physics, Los Alamos National Laboratory, Los Alamos, New Mexico 87545
}

Received: March 31, 2000

\begin{abstract}
The reaction chemistry in the afterglow of a non-equilibrium, capacitive discharge, operated at 600 Torr total pressure with $(0.5$ to 5.0$) \times 10^{17} \mathrm{~cm}^{-3}$ of oxygen in helium, has been examined by ultraviolet absorption spectroscopy, optical emission spectroscopy, and numerical modeling. The densities of the active species, $\mathrm{O}\left({ }^{3} \mathrm{P}\right), \mathrm{O}_{2}\left({ }^{1} \Delta_{\mathrm{g}}\right), \mathrm{O}_{2}\left({ }^{1} \Sigma_{\mathrm{g}}{ }^{+}\right)$, and $\mathrm{O}_{3}$, have been determined as a function of the operating conditions. At RF power densities between 6.1 and $30.5 \mathrm{~W} / \mathrm{cm}^{3}$ and a neutral temperature of $100 \pm 40^{\circ} \mathrm{C}$, the plasma generated (0.2 to 1.0$) \times 10^{16} \mathrm{~cm}^{-3}$ of $\mathrm{O}\left({ }^{3} \mathrm{P}\right)$ and $\mathrm{O}_{2}\left({ }^{1} \Delta_{\mathrm{g}}\right),(0.2$ to 2.0$) \times 10^{15} \mathrm{~cm}^{-3}$ of $\mathrm{O}_{2}\left({ }^{1} \Sigma_{\mathrm{g}}{ }^{+}\right)$, and $(0.1$ to 4.0$) \times 10^{15}$ $\mathrm{cm}^{-3}$ of $\mathrm{O}_{3}$. After the power was turned off, the singlet-sigma and singlet-delta states decayed within 0.1 and $30.0 \mathrm{~ms}$, respectively. The concentration of oxygen atoms remained constant for about $0.5 \mathrm{~ms}$, then fell rapidly due to recombination with $\mathrm{O}_{2}$ to form $\mathrm{O}_{3}$. It was found that the etching rate of polyimide correlated with the concentration of oxygen atoms in the afterglow, indicating that the $\mathrm{O}$ atoms were the active species involved in this process.
\end{abstract}

\section{Introduction}

Oxygen plasmas, containing 1-10 Torr of $\mathrm{O}_{2}$, are widely used for ashing photoresist films on semiconductor wafers. ${ }^{1-3}$ In this process, the substrate is placed downstream of the region of gas excitation, since it is undesirable for ions to bombard the substrate and potentially damage the thin dielectric layers. Although the afterglow region of oxygen plasmas has been studied for a long time ${ }^{4-7}$ there are still many uncertainties with regard to the reaction chemistry, particularly how the distribution of reactive oxygen species affects materials processes carried out downstream. Today, complex photoresists are being developed to transfer smaller and smaller patterns onto semiconductor surfaces. ${ }^{8}$ This requires that the plasma chemistry be fine-tuned to selectively etch the material without attacking and undercutting any of the underlying films. A thorough knowledge of the reaction chemistry would greatly assist in the achievement of this goal.

Recently, we have developed a plasma source that operates at atmospheric pressure and neutral temperatures between 100 and $200{ }^{\circ} \mathrm{C} .{ }^{9-12} \mathrm{~A}$ stable, homogeneous, arc-less gas discharge was created by flowing gas composed primarily of helium between two closely spaced metal electrodes driven with RF power at $13.56 \mathrm{MHz}$. Addition of 1 to 10 Torr of oxygen to the gas feed yielded a high concentration of reactive species that was capable of etching polyimide and other organic films at rates in excess of $10 \mu \mathrm{m} / \mathrm{min} .^{9,10}$ In this regard, our source was similar to a pure oxygen discharge operated at 1 to 10 Torr total pressure. However, an atmospheric-pressure plasma can offer several advantages over a low-pressure plasma, such as reduced ion damage.

In this paper, we have characterized the afterglow of an atmospheric-pressure oxygen plasma using time-resolved ultraviolet absorption and optical emission spectroscopy, and nu-

* To whom correspondence should be addressed. E-mail: rhicks@ucla.edu.

$\doteqdot$ University of California.

$\doteqdot$ Los Alamos National Laboratory. merical modeling of the reaction kinetics. This approach provides a new method for determining the concentration of ground-state oxygen atoms in a downstream plasma process. Ten microseconds after turning off the RF power, the reaction mechanism may be adequately described with six species: ground-state $\mathrm{O}_{2}$, ground-state $\mathrm{He}$, ground-state $\mathrm{O}$ atoms $\left({ }^{3} \mathrm{P}\right)$, metastable molecular $\mathrm{O}_{2}\left({ }^{1} \Delta_{\mathrm{g}}\right.$ and $\left.{ }^{1} \Sigma_{\mathrm{g}}{ }^{+}\right)$, and ozone. The dependence of the latter four reactive species on the plasma operating conditions has been determined. These results are important for understanding how atmospheric-pressure plasmas may be utilized in semiconductor processing, e.g., for the ashing of photoresist films.

\section{Experimental Methods}

Apparatus. A schematic of the plasma source used in this study is presented in Figure 1. It consisted of two parallel-plate electrodes made of aluminum, and separated by a gap $1.6 \mathrm{~mm}$ in height. The lower electrode was $10.2 \mathrm{~cm}$ wide by $5.5 \mathrm{~cm}$ long and was driven by RF power at $13.56 \mathrm{MHz}$, while the upper electrode was $10.2 \mathrm{~cm}$ wide by $20.4 \mathrm{~cm}$ long and was grounded. Just downstream of the lower electrode was an aluminum oxide plate, $10.2 \times 10.2 \mathrm{~cm}^{2}$, which avoided any disturbance of the gas flow in the afterglow region. The sides of the duct parallel to the flow direction were sealed with quartz windows so that spectroscopic measurements of the gas could be made. A slit was placed across the flow path upstream of the plasma to provide for a uniform flow velocity across the duct. The neutral gas temperature was recorded as a function of the process conditions with an ungrounded thermocouple, $0.8 \mathrm{~mm}$ in diameter. To make the measurement, it was momentarily inserted into the gas flow just $5 \mathrm{~mm}$ downstream of the powered electrode.

The plasma was operated with helium and oxygen gas mixtures at 600 Torr total pressure (ambient conditions at Los Alamos National Laboratory), and a flow velocity of $5.2 \mathrm{~m} / \mathrm{s}$ (at $25{ }^{\circ} \mathrm{C}$ and 600 Torr). This corresponds to a Reynold's 


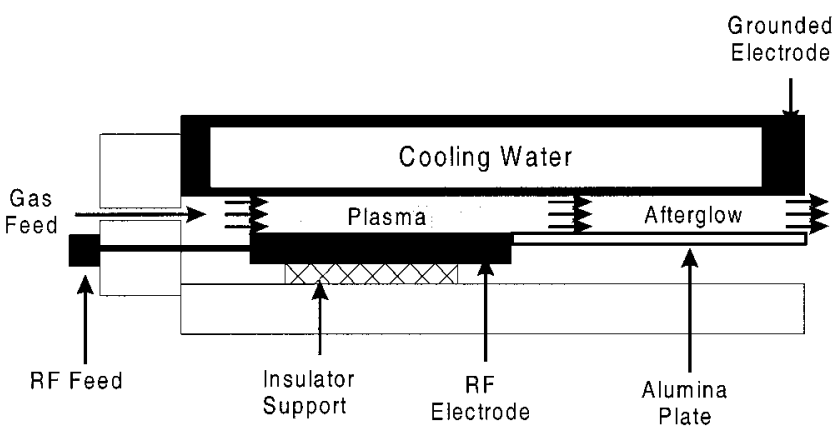

(a)

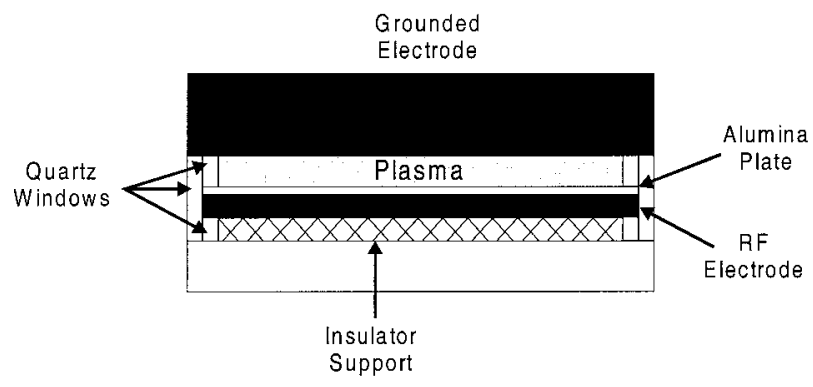

(b)

Figure 1. Schematic of the parallel-plate plasma: (a) side view, and (b) front view.

number of 22.4, which is well within the laminar-flow regime. The oxygen partial pressure in the plasma was varied from 1.0 to 15.0 Torr, while holding the RF power constant at $400 \mathrm{~W}$ $\left(24.4 \mathrm{~W} / \mathrm{cm}^{3}\right)$ and the gas temperature at $120{ }^{\circ} \mathrm{C}$. Conversely, the RF power was varied from 100 to $500 \mathrm{~W}$ (6.1 to 30.5 $\mathrm{W} / \mathrm{cm}^{3}$ ), while keeping the oxygen partial pressure at 6.0 Torr. The gas temperature depended on the applied power, increasing from $50{ }^{\circ} \mathrm{C}$ at $100 \mathrm{~W}$ to $140{ }^{\circ} \mathrm{C}$ at $500 \mathrm{~W}$.

Ozone. Ultraviolet absorption spectroscopy was used to acquire the ozone concentration in the plasma and the downstream afterglow as a function of the process conditions. A schematic of the optical setup is shown in Figure 2 a. A mercury/ argon lamp was mounted on one side of the plasma, while a quartz fiber-optic bundle was placed on the other side. Pinholes, approximately $1 \mathrm{~mm}$ in diameter, were placed in front of the lamp and the bundle to eliminate any stray light. Light passed through the fiber-optic bundle into a monochromator, and then was detected by either a UV-enhanced, charged-coupled device (CCD), or a photomultiplier tube (PMT). The monochromator had a focal length of $640 \mathrm{~mm}$, a slit width of $150 \mu \mathrm{m}$, and a grating with 2400 grooves $/ \mathrm{mm}$. The average absolute concentration of the ozone in the plasma was calculated from the reduction in the $\mathrm{Hg} \mathrm{I}$ emission intensity at $253.7 \mathrm{~nm}$. It is noted that the absorption cross-section of $\mathrm{O}_{3}$ at this wavelength, $1.16 \times 10^{-17}$ $\mathrm{cm}^{2}$, is much larger than the absorption cross-section of the weak Herzberg continuum of $\mathrm{O}_{2},<1 \times 10^{-23} \mathrm{~cm}^{2} .{ }^{13-15}$

The concentration of ozone was obtained either as a function of axial position during discharge operation, or as a function of time after extinguishing the plasma. For spatially resolved measurements, the intensity of the line at $253.7 \mathrm{~nm}$ was recorded with the CCD, and a spatial resolution of $3 \mathrm{~mm}$ was achieved. For temporally resolved measurements, the light intensity was recorded with the PMT to provide a fast response. The rise time of the photomultiplier tube was $2.3 \mathrm{~ns}$, and the response time of the circuit was $1 \mu \mathrm{s}$. The signal was then digitized at 500 $\mathrm{kHz}$ to provide a time resolution of $2 \mu \mathrm{s}$, while the accuracy of

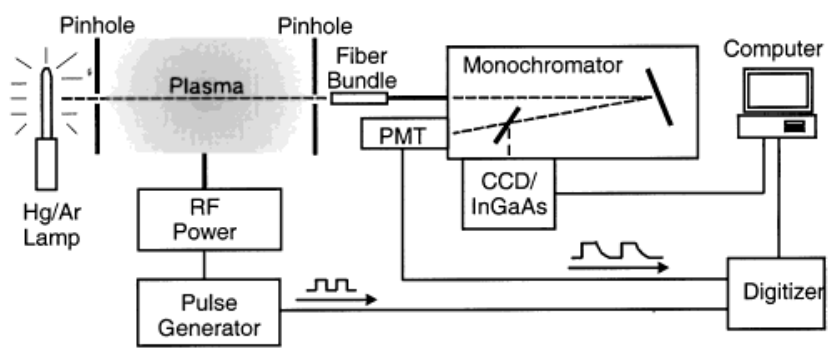

(a)

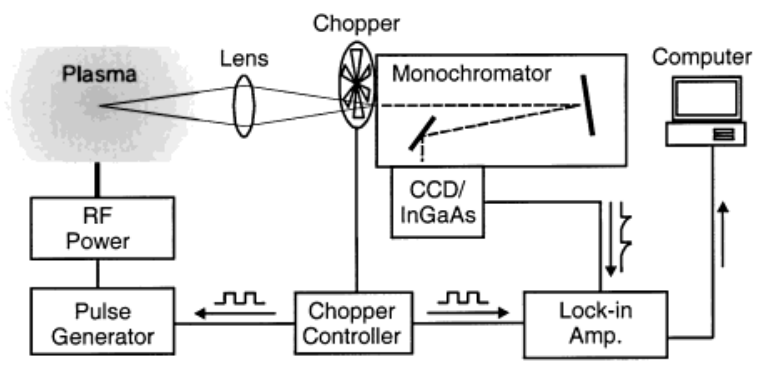

(b)

Figure 2. Diagram of the apparatus used for (a) time-resolved UV absorption and optical emission spectroscopy, and (b) time-averaged infrared emission spectroscopy without interference from background emission from the plasma.

the triggering was better than $1 \mu \mathrm{s}$. Transient signals collected this way were average over 16 traces. The discharge was pulsed at $0.5 \mathrm{~Hz}$ with a $50 \%$ duty cycle for the afterglow experiments. This ensured that steady state was achieved prior to plasma extinction.

Singlet-Sigma Metastable Oxygen. Optical emission spectroscopy was used to record the concentration of singlet-sigma metastable oxygen, $\mathrm{O}_{2}\left({ }^{1} \sum_{\mathrm{g}}{ }^{+}\right)$, and the $\mathrm{R}$ and $\mathrm{P}$ branches are centered at 759.9 and $764.5 \mathrm{~nm}$. The same optical setup was used in this case as shown in Figure 2a, except that a slit, 0.1 $\mathrm{mm} \times 0.086 \mathrm{~mm}$, was substituted for the pinhole in front of the fiber-optic bundle. The emission intensity recorded by the monochromator and CCD detector in this region of the spectrum was calibrated with a NIST-traceable, standard tungsten lamp. The integrated intensity, $\bar{I}$, measured by the spectrometer from 757 to $773 \mathrm{~nm}$ is given by

$$
\bar{I}_{\text {lamp }}=\int I_{\text {lamp }} \mathrm{d} \lambda=k F_{\text {lamp }} \times \frac{1}{4 \pi} \times \int S \mathrm{~d} A
$$

where $I$ is the signal intensity recorded, $\lambda$ is the wavelength $(\mathrm{nm}), k$ is the spectrometer calibration constant (nm s/photon), $F$ is the photon flux of the lamp, $2.78 \times 10^{17}$ photons $\mathrm{mm}^{2} \mathrm{~s}^{-1}$, $S$ is the solid angle viewed through the slit, and $A$ is the area $\left(\mathrm{mm}^{2}\right)$ of the lamp sampled.

The integrated intensity of the light emitted by the metastable oxygen is

$$
\bar{I}_{\Sigma}=\int I_{\Sigma} \mathrm{d} \lambda=k R_{\Sigma} \times \frac{1}{4 \pi} \times \int S \mathrm{~d} V
$$

where $R_{\Sigma}$ is the rate of photon emission of the ${ }^{1} \Sigma_{\mathrm{g}}{ }^{+}$state (photons $\mathrm{mm}^{-1} \mathrm{~s}^{-1}$ ), and $\mathrm{V}$ is the volume $\left(\mathrm{mm}^{3}\right)$ of the plasma sampled. The rate of photon emission for the transition $\mathrm{O}_{2}\left(\mathrm{~b}^{1} \Sigma_{\mathrm{g}}{ }^{+}\right)$to $\mathrm{O}_{2}\left(\mathrm{X}^{3} \Sigma_{\mathrm{g}}{ }^{-}\right)$depends on the Einstein $A$-coefficient, $A_{\Sigma}$, and the excited species density, $\left[\mathrm{O}_{2}\left(\mathrm{~b}^{1} \Sigma_{\mathrm{g}}{ }^{+}\right)\right]$as

$$
R_{\Sigma}=A_{\Sigma}\left[\mathrm{O}_{2}\left(\mathrm{~b}^{1} \Sigma_{\mathrm{g}}^{+}\right)\right]
$$




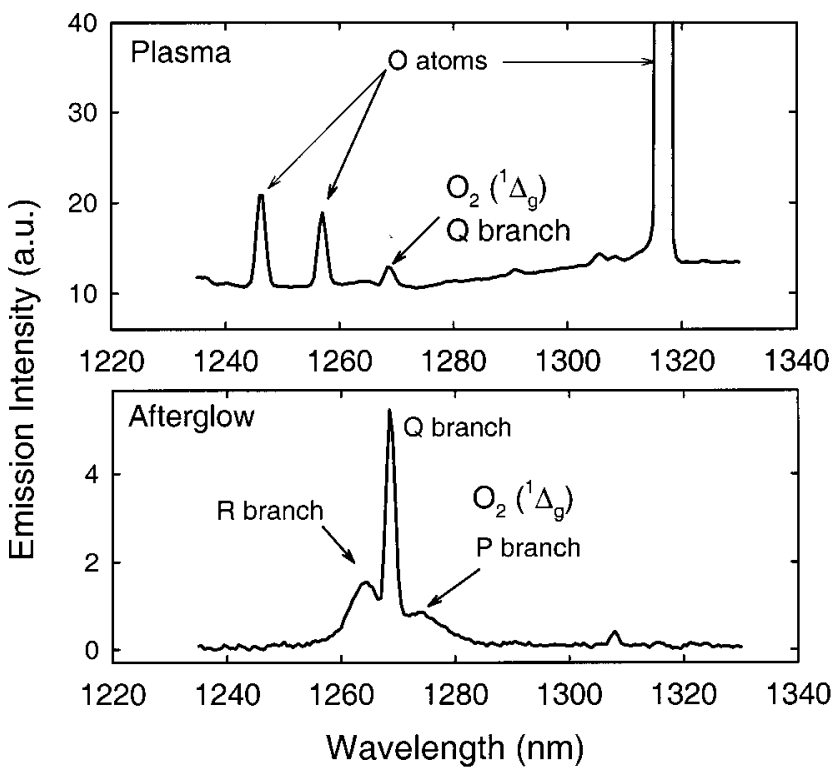

Figure 3. Infrared emission spectrum of the plasma and the afterglow for operation at $24.4 \mathrm{~W} / \mathrm{cm}^{3}, 6.0$ Torr of $\mathrm{O}_{2}$ and $120{ }^{\circ} \mathrm{C}$.

The value used for the Einstein $A$-coefficient is $0.085 \mathrm{~s}^{-1}$, and corresponds to a 0 to 0 vibrational transition. ${ }^{16}$ Higher vibrational levels are not considered, because the neutral temperature of the plasma is about $373 \mathrm{~K}$, whereas the equivalent energy of the first vibrational state is more than $2000 \mathrm{~K} .{ }^{16}$ The spectrometer calibration constant is obtained from eq 1 , then used in eq 2 to determine the emission rate, $R_{\Sigma}$, from the integrated intensity of the bands. Finally, the concentration of ${ }^{1} \Sigma_{\mathrm{g}}{ }^{+} \mathrm{O}_{2}$ is obtained from eq 3. Transient measurements of the singlet-sigma metastable emission were also obtained using the pulsed plasma as described above. The standard deviations in these experiments are within $50 \%$.

Singlet-Delta Metastable Oxygen. Singlet-delta metastable oxygen, $\mathrm{O}_{2}\left({ }^{1} \Delta_{\mathrm{g}}\right)$, emits in the infrared between 1.2 and 1.3 $\mu \mathrm{m} .{ }^{16,17}$ To record this spectrum, a liquid nitrogen cooled InGaAs detector was employed with the monochromator using a 600 groove $/ \mathrm{mm}$ grating blazed at $1.5 \mu \mathrm{m}$ and a slit width of $400 \mu \mathrm{m}$. To increase the collection efficiency of the weak singlet-delta emission, the fiber-optic bundle was replaced with a lens assembly. Shown in Figure 3 is a spectrum recorded of the plasma while RF power was being applied to the electrodes. Peaks at 1246, 1257, and $1316 \mathrm{~nm}$ are observed due to emission from oxygen atoms. The Q branch of the metastable spectrum is barely visible above the continuum at $1269 \mathrm{~nm}$.

To eliminate the background, a lock-in amplifier was utilized with an optical chopper, which was mounted in front of the lens as indicated in Figure 2b, and run at 50 and $100 \mathrm{~Hz}$. The RF power supply was pulsed by the trigger signal with a duty factor of $45 \%$. By adjusting the delay between the chopper and the RF power supply, only the light emitted during the afterglow was allowed to enter the spectrometer. The signal from the InGaAs detector was passed through a lock-in amplifier and on to an A/D converter and the computer for data acquisition. The signal varied as the monochromator swept through the wavelengths, thereby producing the singlet-delta spectrum shown in the lower half of Figure 3. Clearly visible are the P, $\mathrm{Q}$, and R branches at 1264, 1269, and $1274 \mathrm{~nm}$. The spectral resolution was $0.5 \mathrm{~nm}$.

The singlet-delta emission, $\mathrm{O}_{2}\left(\mathrm{a}^{1} \Delta_{\mathrm{g}}\right)$ to $\mathrm{O}_{2}\left(\mathrm{X}^{3} \Sigma_{\mathrm{g}}^{-}\right)$is very weak, a hundred times less intense than the singlet-sigma emission, $\mathrm{O}_{2}\left(\mathrm{~b}^{1} \Sigma_{\mathrm{g}}{ }^{+}\right)$to $\mathrm{O}_{2}\left(\mathrm{X}^{3} \Sigma_{\mathrm{g}}^{-}\right)$. This makes calibration directly from the mercury/argon lamp difficult. An alternative solution that we employed was to bridge the intensity range between the lamp and the singlet-delta signal using the moderately intense helium line at $1083 \mathrm{~nm}$. Using eqs $1-3$ above, but with the Einstein coefficient for the delta state, 2.58 $\times 10^{-4} \mathrm{~s}^{-1}, 16$ the concentration of $\mathrm{O}_{2}\left(\mathrm{a}^{1} \Delta_{\mathrm{g}}\right)$ was obtained for one operating condition of $400 \mathrm{~W}$ RF power and 6 Torr of oxygen. This measurement provided a calibration factor (concentration/signal intensity) that could be used for other process conditions, where the signal was recorded as described below.

To determine the concentration of singlet-delta oxygen at other conditions, the signal intensity of the Q branch at 1269 $\mathrm{nm}$ was collected using the chopper arrangement depicted in Figure $2 \mathrm{~b}$. The detector signal decayed after the RF power pulse due to the reaction of $\mathrm{O}_{2}\left(\mathrm{a}^{1} \Delta_{\mathrm{g}}\right)$ with $\mathrm{O}_{3}$. The rate of this reaction is given by $6.01 \times 10^{-11} \exp (-2853 / T) \times\left[\mathrm{O}_{3}\right] \times\left[\mathrm{O}_{2}{ }^{1} \Delta_{\mathrm{g}}\right] .{ }^{18}$ Since the concentration of ozone is known as a function of the process conditions from the UV absorption measurements, a mass balance for $\mathrm{O}_{2}\left(\mathrm{a}^{1} \Delta_{\mathrm{g}}\right)$ can be solved to yield a relationship between the initial concentration of $\mathrm{O}_{2}\left(\mathrm{a}^{1} \Delta_{\mathrm{g}}\right)$ and the integral of the concentration dependence on time. The latter integral is proportional to the signal generated by the lock-in amplifier. Therefore, by using the known concentration of singlet-delta oxygen measured at $400 \mathrm{~W}$ and 6 Torr of $\mathrm{O}_{2}$, the concentration at any other plasma condition can be obtained from the mass balance and the signal recorded from the lock-in amplifier. The uncertainty in this measurement is estimated to be within $\pm 50 \%$ of the reported value.

\section{Model}

A numerical model has been developed to simulate the chemical kinetics that occurs after the RF power has been turned off for periods of time greater than $10 \mu \mathrm{s}$. After this short time has elapsed, one can neglect the influence of the charged species and the metastable states of helium and oxygen atoms on the reaction chemistry. In this case, the only species that need to be included in the kinetic model are ground-state $\mathrm{O}_{2}, \mathrm{O}_{3}, \mathrm{He}$, and $\mathrm{O}$ atoms, and the two forms of metastable $\mathrm{O}_{2}, \mathrm{a}^{1} \Delta_{\mathrm{g}}$ and $\mathrm{b}^{1} \sum_{\mathrm{g}}{ }^{+}$. This assumption is justified on the basis of calculations of the lifetimes of the charged particles and the metastable atoms. The recombination coefficient for ions and electrons at atmospheric pressure is approximately $10^{-6} \mathrm{~cm}^{3} / \mathrm{s},{ }^{19}$ yielding a charged particle density of only $10^{11} \mathrm{~cm}^{-3}$ after $10 \mu \mathrm{s}$. This value is well below the concentrations of the reactive neutral species, which are in the range of $10^{15} \mathrm{~cm}^{-3}$ (see below).

With regard to metastable $\mathrm{He}\left({ }^{3} \mathrm{~S}_{1}\right)$ and $\mathrm{O}\left({ }^{1} \mathrm{D}\right)$, these excited states are rapidly quenched by reaction with $\mathrm{O}_{2}$. Both exhibit a pseudo first-order rate constant of about $10^{7} \mathrm{~s}^{-1}$ at $\mathrm{O}_{2}$ concentrations of $10^{17} \mathrm{~cm}^{-3} \cdot{ }^{20,21}$ Consequently, their lifetimes are only $0.1 \mu \mathrm{s}$ in our experiments. Similarly, metastable $\mathrm{O}\left({ }^{1} \mathrm{~S}\right)$ is quenched by reaction with $\mathrm{O}_{3}$. Given a rate constant of 5.8 $\times 10^{-10} \mathrm{~cm}^{3} / \mathrm{s},{ }^{22}$ and an ozone concentration of $2 \times 10^{15} \mathrm{~cm}^{-3}$, the lifetime of this metastable state is less than $1 \mu \mathrm{s}$.

The transient material balance for each of the six species considered in the model is

$$
\frac{\mathrm{d}[\mathrm{X}]}{\mathrm{d} t}=\sum_{i} \mathrm{R}_{i}
$$

where $[\mathrm{X}]$ is the concentration of species $\mathrm{X}$, and $\mathrm{R}_{i}$ is the rate of reaction $i$ that either produces or consumes $\mathrm{X}$. The reactions employed and the corresponding kinetic constants are presented in Table 1. A thermal energy balance was not required, because the system may be assumed to be isothermal. A maximum adiabatic temperature rise of $0.1{ }^{\circ} \mathrm{C}$ was calculated. The set of 
TABLE 1: Reactions and Their Kinetic Constants

\begin{tabular}{|c|c|c|c|}
\hline & reactions & rate constants $\left(\mathrm{cm}^{3}\right.$ molecule $\left.^{-1} \mathrm{~s}^{-1}\right)$ & re \\
\hline $\mathrm{R}_{1}$ & $\mathrm{O}+\mathrm{O}+\mathrm{M} \rightarrow \mathrm{O}_{2}+\mathrm{M}$ & $5.2 \times 10^{-35} \cdot \exp (900 / T)^{*, \dagger}$ & \\
\hline $\mathrm{R}_{2}$ & $\mathrm{O}+\mathrm{O}_{2}+\mathrm{M} \rightarrow \mathrm{O}_{3}+\mathrm{M}$ & $1.85 \times 10^{-35} \cdot \exp (1057 / T)^{*, \neq}$ & \\
\hline $\mathrm{R}_{3}$ & $\mathrm{O}+\mathrm{O}_{3} \rightarrow \mathrm{O}_{2}+\mathrm{O}_{2}$ & $1.5 \times 10^{-11} \cdot \exp (-2250 / T)$ & \\
\hline $\mathrm{R}_{4}$ & $\mathrm{O}_{3}+\mathrm{M} \rightarrow \mathrm{O}+\mathrm{O}_{2}+\mathrm{M}$ & $7.26 \times 10^{-10} \cdot \exp (-11400 / T)^{\ddagger}$ & \\
\hline $\mathrm{R}_{5}$ & $\mathrm{O}_{2}\left({ }^{1} \Delta_{\mathrm{g}}\right)+\mathrm{He} \rightarrow \mathrm{O}_{2}+\mathrm{He}$ & $8.0 \times 10^{-21}$ & \\
\hline $\mathrm{R}_{6}$ & $\mathrm{O}_{2}\left({ }^{1} \Delta_{\mathrm{g}}\right)+\mathrm{O}_{2} \rightarrow 2 \mathrm{O}_{2}$ & $5.0 \times 10^{-18} \cdot \exp (-280 / T)$ & \\
\hline $\mathrm{R}_{7}$ & $\mathrm{O}_{2}\left({ }^{1} \Delta_{\mathrm{g}}\right)+\mathrm{O} \rightarrow \mathrm{O}_{2}+\mathrm{O}$ & $1.65 \times 10^{-16}$ & \\
\hline $\mathrm{R}_{8}$ & $\mathrm{O}_{2}\left({ }^{1} \Delta_{\mathrm{g}}\right)+\mathrm{O}_{3} \rightarrow \mathrm{O}+2 \mathrm{O}_{2}$ & $6.01 \times 10^{-11} \cdot \exp (-2853 / T)$ & \\
\hline $\mathrm{R}_{9}$ & $\mathrm{O}_{2}\left({ }^{1} \Delta_{\mathrm{g}}\right) \rightarrow \mathrm{O}_{2}+h v$ & $3.7 \times 10^{-4 \S}$ & \\
\hline $\mathrm{R}_{10}$ & $2 \mathrm{O}_{2}\left({ }^{1} \Delta_{\mathrm{g}}\right) \rightarrow \mathrm{O}_{2}\left({ }^{1} \Sigma_{\mathrm{g}}^{+}\right)+\mathrm{O}_{2}$ & $1.81 \times 10^{-19} \cdot(T / 300)^{3.8} \cdot \exp (700 / T)$ & \\
\hline $\mathrm{R}_{11}$ & $\mathrm{O}_{2}\left({ }^{1} \Sigma_{\mathrm{g}}^{+}\right)+\mathrm{He} \rightarrow \mathrm{O}_{2}+\mathrm{He}$ & $1.0 \times 10^{-17}$ & \\
\hline $\mathrm{R}_{12}$ & $\mathrm{O}_{2}\left({ }^{1} \Sigma_{\mathrm{g}}{ }^{+}\right)+\mathrm{O}_{2} \rightarrow 2 \mathrm{O}_{2}$ & $1.0 \times 10^{-16}$ & \\
\hline $\mathrm{R}_{13}$ & $\mathrm{O}_{2}\left({ }^{1} \Sigma_{\mathrm{g}}{ }^{+}\right)+\mathrm{O} \rightarrow \mathrm{O}_{2}+\mathrm{O}$ & $8.0 \times 10^{-14}$ & \\
\hline $\mathrm{R}_{14}$ & $\mathrm{O}_{2}\left({ }^{1} \Sigma_{\mathrm{g}}{ }^{+}\right)+\mathrm{O}_{3} \rightarrow \mathrm{O}+2 \mathrm{O}_{2}$ & $1.5 \times 10^{-11}$ & \\
\hline $\mathrm{R}_{15}$ & $\mathrm{O}_{2}\left({ }^{1} \Sigma_{\mathrm{g}}^{+}\right) \rightarrow \mathrm{O}_{2}+h v$ & $0.14^{\S}$ & \\
\hline
\end{tabular}

$*$ Unit $[=] \mathrm{cm}^{6} / \mathrm{molecules}^{2} / \mathrm{s}$. Collision efficiencies, 0.62 for $\mathrm{He}$ and 1.15 for $\mathrm{O}_{2}$. $¥$ Collision efficiencies, 1.0 for oxygen and 0.54 for $\mathrm{He}, 0.13$ for $\mathrm{O}, 2.27$ for $\mathrm{O}_{3} .{ }^{\S}$ Unit $[=] 1 / \mathrm{s}$.



Figure 4. The dependence of the ozone concentration on axial position and oxygen partial pressure for an applied power of $24.4 \mathrm{~W} / \mathrm{cm}^{3}$ and a gas temperature of $120^{\circ} \mathrm{C}$.

five coupled, first-order differential equations were solved by the Runge-Kutta method using a Fortran program. The concentrations of all the species, except the ground-state oxygen atoms, were known at the initial condition, $t=10 \mu \mathrm{s}$. The latter concentration was obtained by trial and error: different values were input to the model until a best fit was obtained to the measured concentration profiles for $\mathrm{O}_{2}\left({ }^{1} \Sigma_{\mathrm{g}}{ }^{+}\right)$and $\mathrm{O}_{3}$. The rate constants obtained from the literature were used without modification.

\section{Results and Discussion}

Concentration of the Reactive Species. Shown in Figure 4 are axial concentration profiles for ozone at different inlet pressures of oxygen. The plasma is observed over the RF electrode, which extends for $55.0 \mathrm{~mm}$ in the axial flow direction. For $\mathrm{O}_{2}$ pressures below 10 Torr, the ozone concentration reaches a steady-state value $10 \mathrm{~mm}$ past the leading edge of the powered electrode. At 11.4 and 15.2 Torr of $\mathrm{O}_{2}$, steady state is achieved at a distance of $30 \mathrm{~mm}$. A similar behavior is observed for the singlet-sigma metastable oxygen emission. It should be noted that time-resolved measurements of the afterglow taken in the pulsed-plasma mode were acquired with the beam path directed across the duct at an axial distance of $45 \mathrm{~mm}$.

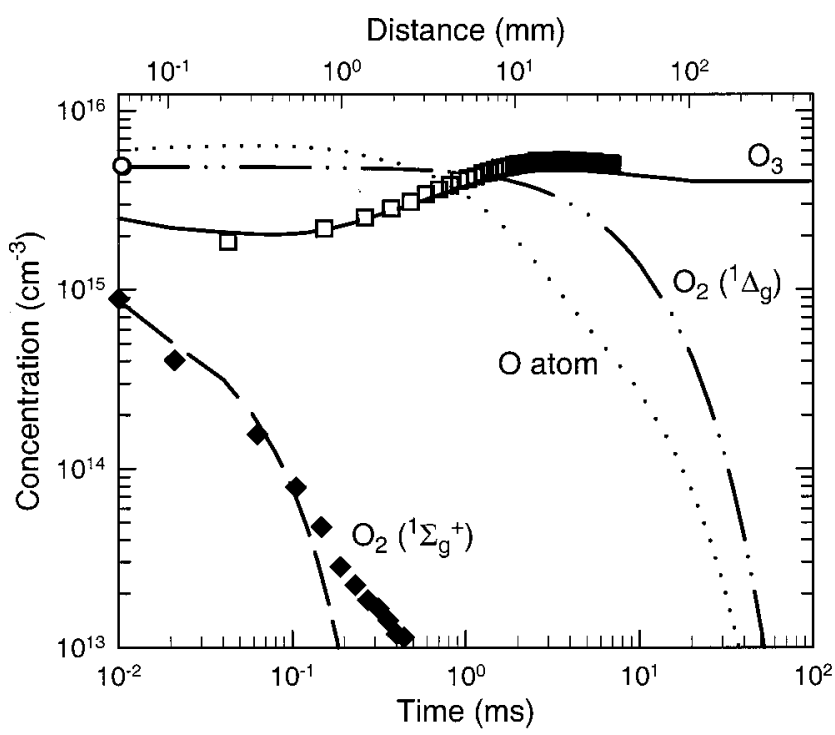

Figure 5. The dependence of the $\mathrm{O}, \mathrm{O}_{2}\left({ }^{1} \Delta_{\mathrm{g}}\right), \mathrm{O}_{2}\left({ }^{1} \Sigma_{\mathrm{g}}{ }^{+}\right)$, and $\mathrm{O}_{3}$ concentrations on time and distance for initial plasma operation at 24.4 $\mathrm{W} / \mathrm{cm}^{3}, 6.0$ Torr of $\mathrm{O}_{2}$, and $120^{\circ} \mathrm{C}$ (symbols are the experimental data, whereas the lines are the model prediction).

As the gas emerges from the plasma at $55 \mathrm{~mm}$, the concentration of ozone rapidly increases and approaches a new steady-state value at a distance of about $80 \mathrm{~mm}$. The jump in ozone concentration in the afterglow rises with the oxygen partial pressure. At 15.2 Torr of $\mathrm{O}_{2}$, the $\mathrm{O}_{3}$ concentrations inside and outside the plasma are 0.4 and $1.0 \times 10^{16} \mathrm{~cm}^{-3}$, respectively. The change in ozone concentration is due to the reaction of $\mathrm{O}$ atoms with $\mathrm{O}_{2}\left(\mathrm{R}_{2}\right.$ in Table 1$)$, and is an approximate measure of the $\mathrm{O}$ atom concentration in the plasma, $\sim 6 \times 10^{15}$ $\mathrm{cm}^{-3}$.

Presented in Figure 5 is the evolution of the oxygen atoms, metastable oxygen molecules, and ozone with time after turning off the power to the electrode. The curves are the concentrations predicted from the numerical model, whereas the symbols are the experimental data. Excellent agreement is achieved between the theory and the experiment, without any adjustment to the rate constants. At time $t=10 \mu \mathrm{s}$ after the RF power is shut off, the concentrations of the five oxygen species are $1.3 \times$ $10^{17} \mathrm{~cm}^{-3}$ ground-state $\mathrm{O}_{2}, 6.0 \times 10^{15} \mathrm{~cm}^{-3} \mathrm{O}$ atoms, $5.0 \times$ $10^{15} \mathrm{~cm}^{-3} \mathrm{O}_{2}\left({ }^{1} \Delta_{\mathrm{g}}\right), 1.0 \times 10^{15} \mathrm{~cm}^{-3} \mathrm{O}_{2}\left({ }^{1} \Sigma_{\mathrm{g}}{ }^{+}\right)$, and $2.5 \times 10^{15}$ $\mathrm{cm}^{-3} \mathrm{O}_{3}$. Assuming the concentrations of the neutral species are continuous from the on- to the off-state, these results indicate that the plasma converts $2 \%$ and $3.5 \%$ of the oxygen fed into $\mathrm{O}$ atoms and singlet-delta metastable $\mathrm{O}_{2}$ molecules, respectively, at 6 Torr of $\mathrm{O}_{2}$ and $24.4 \mathrm{~W} / \mathrm{cm}^{3}$ (400 W applied power).

After the discharge has been extinguished, the oxygen atoms rapidly recombine with oxygen molecules to produce ozone. The ozone concentration climbs to a constant value of $5 \times 10^{15}$ $\mathrm{cm}^{-3}$ after about $3 \mathrm{~ms}$, and does not change further. Note that the half-life of ozone decaying via reaction $\mathrm{R}_{4}$ is $200 \mathrm{~s}$ at 120 ${ }^{\circ} \mathrm{C}$. After $3 \mathrm{~ms}$, the concentration of oxygen atoms has declined to about $1.0 \times 10^{15} \mathrm{~cm}^{-3}$. Thereafter, the amount of this species falls rapidly. The two metastable oxygen molecules, $\left({ }^{1} \Delta_{\mathrm{g}}\right)$ and $\left({ }^{1} \Sigma_{\mathrm{g}}{ }^{+}\right)$, exhibit dramatically different decay rates. The singletdelta state persists out to about $10 \mathrm{~ms}$, whereas the singletsigma state is essentially extinguished by $500 \mu \mathrm{s}$. The consumption rate of both of these species is governed by their reaction with ozone, $\mathrm{R}_{8}$ and $\mathrm{R}_{14}$, respectively. The ratio of the rate constants for these two reactions at $120{ }^{\circ} \mathrm{C}$ is $k_{8} / k_{14}=$ 0.0038 . 


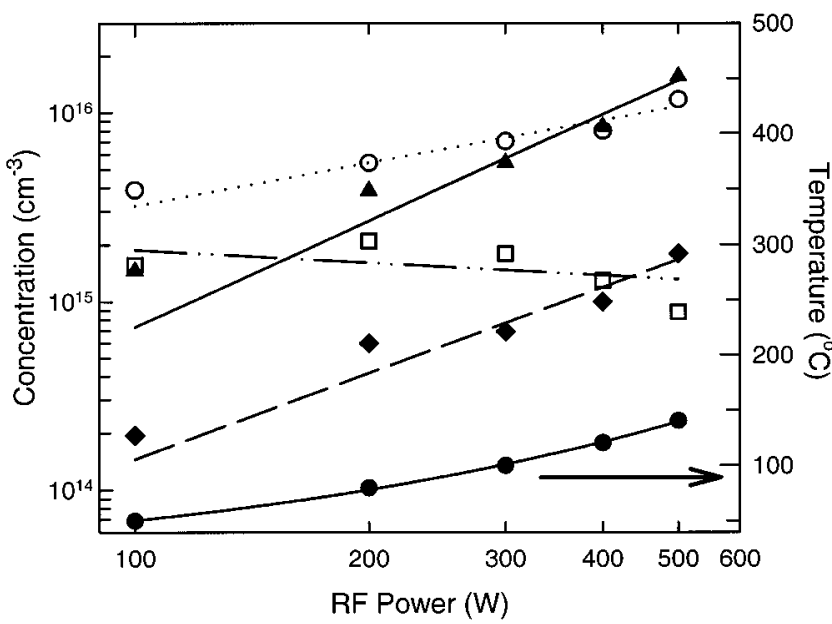

Figure 6. The effect of the $\mathrm{RF}$ power on the concentrations of $\mathrm{O}$ atoms $(\boldsymbol{\Delta}), \mathrm{O}_{2}\left({ }^{1} \Delta_{\mathrm{g}}\right)(\mathrm{O}), \mathrm{O}_{2}\left({ }^{1} \Sigma_{\mathrm{g}}{ }^{+}\right)(\diamond), \mathrm{O}_{3}(\square)$, and temperature $(\bullet)$ at 6.0 Torr $\mathrm{O}_{2}$

In Figure 5, distance is plotted on the upper $x$ axis so that one can also examine how the reaction evolves as the gas travels downstream in the afterglow region. The linear velocity of the gas between the electrodes is $5.2 \mathrm{~m} / \mathrm{s}$, so that $1 \mathrm{~mm}$ equals 192 $\mu \mathrm{s}$. It is interesting to note that the spatial resolution of the measurements was $3 \mathrm{~mm}$. By contrast, the resolution obtained with the transient measurements was $2 \mu \mathrm{s}$, a 300-fold improvement. Inspection of the figure reveals that the concentration of oxygen atoms remains constant out to $1 \mathrm{~mm}$, then drops by a factor of 3 on going from 1 to $10 \mathrm{~mm}$. Since the $\mathrm{O}$ atoms are the most reactive species, and would be desired in many materials-processing applications, these results suggest that the substrate should be placed within 1 to $2 \mathrm{~mm}$ of the exit of the plasma.

Shown in Figure 6 is the effect of the RF power on the concentrations of $\mathrm{O}$ atoms, $\mathrm{O}_{2}\left({ }^{1} \Delta_{\mathrm{g}}\right), \mathrm{O}_{2}\left({ }^{1} \Sigma_{\mathrm{g}}{ }^{+}\right)$, and $\mathrm{O}_{3}$, which are present $10 \mu$ s after the RF power has been turned off. Note that the neutral temperature in the plasma rises from $60{ }^{\circ} \mathrm{C}$ at $100 \mathrm{~W}$ to $140{ }^{\circ} \mathrm{C}$ at $500 \mathrm{~W}$. The $\log -\log$ plot shows that all the species increase with the RF power except for ozone. The slopes of the "best-fit" lines yield the following dependencies: $\mathrm{O} \propto P_{\mathrm{RF}}{ }^{1.9}, \mathrm{O}_{2}\left({ }^{1} \Delta_{\mathrm{g}}\right) \propto P_{\mathrm{RF}}{ }^{0.8}, \mathrm{O}_{2}\left({ }^{1} \Sigma_{\mathrm{g}}{ }^{+}\right) \propto P_{\mathrm{RF}}{ }^{1.5}$, and $\mathrm{O}_{3} \propto$ $P_{\mathrm{RF}}{ }^{-0.2}$.

Presented in Figure 7 is the effect of the oxygen partial pressure on the concentrations of $\mathrm{O}$ atoms, $\mathrm{O}_{2}\left({ }^{1} \Delta_{\mathrm{g}}\right), \mathrm{O}_{2}\left({ }^{1} \Sigma_{\mathrm{g}}{ }^{+}\right)$, and $\mathrm{O}_{3}$, which are present $10 \mu$ s after the RF power has been turned off. Except for singlet-sigma metastable oxygen, the concentrations of the reactive species increase with the oxygen pressure throughout the range studied. The strongest dependence is seen for ozone, as expected because it requires two oxygen molecules to be produced. The dependencies on oxygen pressure obtained from the best-fit lines to the data are $\mathrm{O} \propto P_{\mathrm{O}_{2}}{ }^{0.6}, \mathrm{O}_{2}$ $\left({ }^{1} \Delta_{\mathrm{g}}\right) \propto \mathrm{P}_{\mathrm{O}_{2}}{ }^{0.5}, \mathrm{O}_{2}\left({ }^{1} \Sigma_{\mathrm{g}}{ }^{+}\right) \propto \mathrm{P}_{\mathrm{O}_{2}}{ }^{-0.2}$, and $\mathrm{O}_{3} \propto \mathrm{P}_{\mathrm{O}_{2}}{ }^{1.5}$.

Shibata et al. ${ }^{30}$ have modeled the structure of an oxygen discharge in a parallel-plate reactor driven with $150 \mathrm{~W}$ RF power at $13.56 \mathrm{MHz}$ and a total oxygen pressure of 0.5 Torr. They predict an average number density for oxygen atoms of $\sim 3 \times$ $10^{14} \mathrm{~cm}^{-3}$. Extrapolating the data in Figures 6 and 7 to 0.5 Torr of $\mathrm{O}_{2}$ and $150 \mathrm{~W}$, yields a value of $\sim 5 \times 10^{14} \mathrm{~cm}^{-3}$ for our glow discharge source. This value is in good agreement with Shibata's work.

Analysis of the Reaction Kinetics. A series of simulations have been run to determine which reactions listed in Table 1 are kinetically significant. We have found that only seven are needed to describe the chemistry in the afterglow, $R_{1}, R_{2}, R_{3}$,

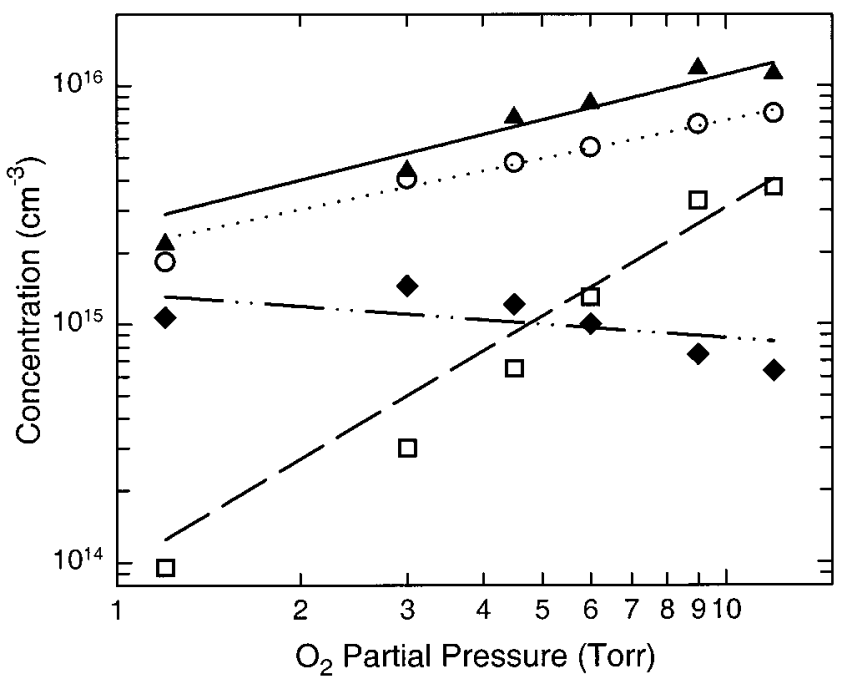

Figure 7. The effect of the oxygen pressure on the concentrations of $\mathrm{O}$ atoms $(\boldsymbol{\Delta}), \mathrm{O}_{2}\left({ }^{1} \Delta_{\mathrm{g}}\right)(\mathrm{O}), \mathrm{O}_{2}\left({ }^{1} \Sigma_{\mathrm{g}}{ }^{+}\right)(\diamond)$, and $\mathrm{O}_{3}(\square)$ at $24.4 \mathrm{~W} / \mathrm{cm}^{3}$ and $120^{\circ} \mathrm{C}$.

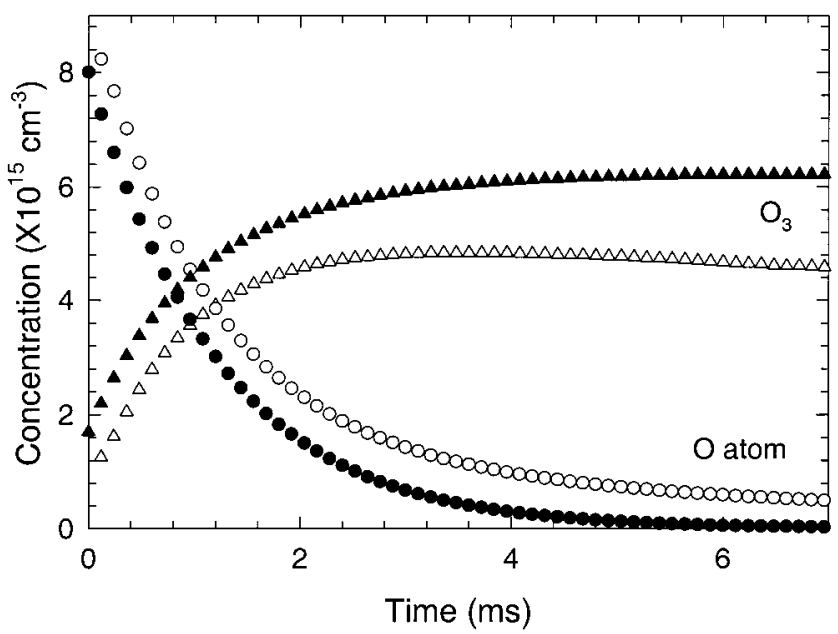

Figure 8. The evolution of the oxygen atom and ozone concentrations with time as predicted from the model with (open symbols) and without (filled symbols) metastable oxygen molecules included. The initial plasma conditions are $24.4 \mathrm{~W} / \mathrm{cm}^{3}, 6.0$ Torr of $\mathrm{O}_{2}$, and $120{ }^{\circ} \mathrm{C}$.

$\mathrm{R}_{8}, \mathrm{R}_{11}, \mathrm{R}_{13}$, and $\mathrm{R}_{14}$. The first three of these, $\mathrm{R}_{1}, \mathrm{R}_{2}$, and $\mathrm{R}_{3}$, consume oxygen atoms, and account for most of the ozone production. The fourth, $\mathrm{R}_{8}$, converts singlet-delta metastable oxygen molecules and ozone into ground-state oxygen atoms and molecules. The last three reactions, $\mathrm{R}_{11}, \mathrm{R}_{13}$, and $\mathrm{R}_{14}$, extinguish the singlet-sigma metastable oxygen molecules by collision with other species in the gas. As shown in Figure 5, the collisional de-excitation of $\mathrm{O}_{2}\left({ }^{1} \Sigma_{\mathrm{g}}{ }^{+}\right)$occurs rapidly within the first hundred microseconds. Since this molecule decays so fast and has a negligible influence on the other reactive species, the mechanism may be simplified further to include just reactions $R_{1}, R_{2}, R_{3}$, and $R_{8}$.

In an earlier study of the atmospheric-pressure plasma, we proposed that the afterglow could be modeled with only three reactions involving the consumption of $\mathrm{O}$ atoms and the production of ozone $\left(\mathrm{R}_{1}, \mathrm{R}_{2}\right.$, and $\left.\mathrm{R}_{3}\right){ }^{10}$ In the present work, we have found that this mechanism must be modified to add in the effects of singlet-delta metastable oxygen. The plasma generates this molecule in about the same abundance as the oxygen atoms. The impact of $\mathrm{O}_{2}\left({ }^{1} \Delta_{\mathrm{g}}\right)$ on the concentrations of $\mathrm{O}$ atoms and $\mathrm{O}_{3}$ in the afterglow is illustrated in Figure 8. The long-lived metastable molecules become a source of oxygen atoms via reaction $\mathrm{R}_{8}$, so that the $\mathrm{O}$ atoms persist for a much 
greater period of time $(>10 \mathrm{~ms})$, albeit at concentrations near $1 \times 10^{14} \mathrm{~cm}^{-3}$. In addition, if the $\mathrm{O}_{2}\left({ }^{1} \Delta_{\mathrm{g}}\right)$ is omitted from the model, it over-predicts the generation of ozone by about $50 \%$.

When all the reactions taking place in the effluent are compared, those that either produce or consume ozone dominate in the afterglow $(t>10 \mu \mathrm{s})$. For example, reaction $\mathrm{R}_{2}$ is about 1 order of magnitude faster than the other significant reactions of $\mathrm{O}$ atoms, $\mathrm{R}_{1}$ and $\mathrm{R}_{3}$. With regard to the metastable molecules, $\mathrm{O}_{2}\left({ }^{1} \Sigma_{\mathrm{g}}{ }^{+}\right)$and $\mathrm{O}_{2}\left({ }^{1} \Delta_{\mathrm{g}}\right)$, they are quenched by ozone at rates that are several hundred times faster than their reactions with other species.

On the basis of experimentally determined concentration profiles for $\mathrm{O}_{2}\left({ }^{1} \Sigma_{\mathrm{g}}{ }^{+}\right)$and $\mathrm{O}_{3}$, the rate constant for $\mathrm{O}_{2}\left({ }^{1} \Sigma_{\mathrm{g}}{ }^{+}\right)$ quenching reaction, $\mathrm{R}_{14}$, can be evaluated. When only this step is considered, the mass balance for $\mathrm{O}_{2}\left({ }^{1} \Sigma_{\mathrm{g}}{ }^{+}\right)$is

$$
\frac{\mathrm{d}\left[\mathrm{O}_{2}{ }^{1} \Sigma_{\mathrm{g}}^{+}\right]}{\mathrm{d} t}=-k_{14}\left[\mathrm{O}_{2}{ }^{1} \Sigma_{\mathrm{g}}^{+}\right]\left[\mathrm{O}_{3}\right]
$$

This form of the rate constant only holds under the assumption that the other reactions involving $\mathrm{O}_{2}\left({ }^{1} \Sigma_{\mathrm{g}}{ }^{+}\right)$are much smaller than its quenching rate with $\mathrm{O}_{3}$. In the afterglow, this is true for about $80 \mu \mathrm{s}$. At longer times, the energy pooling reaction, $\mathrm{R}_{10}$, is comparable in magnitude to $\mathrm{R}_{14}$. At $400 \mathrm{~W}$ and $\mathrm{O}_{2}$ pressures varying from 1 to 12 Torr, an average value of $k_{14}$ has been calculated. In this case, the rate constant equals (1.1 $\pm 0.3) \times 10^{-11} \mathrm{~cm}^{3} / \mathrm{s}$. This number is in good agreement with the value of $1.5 \times 10^{-11} \mathrm{~cm}^{3} / \mathrm{s}$ reported by Watson and coworkers. $^{29}$

Etching Polyimide Films. We have etched polyimide films with the parallel-plate device used in the present study. In this case, the film was placed on the aluminum oxide plate located just downstream of the plasma (Figure 1). The etching rate of the polyimide at $225^{\circ} \mathrm{C}$ equals $4.2 \mu \mathrm{m} / \mathrm{min}$ at the leading edge adjacent to the plasma, but declines rapidly with distance to essentially $0.0 \mu \mathrm{m} / \mathrm{min}$ at $20 \mathrm{~mm}$ downstream. Perusal of Figure 5 reveals that the oxygen atoms are the only reactive species with a decay profile that is similar to the fall-off in the etching rate of the polyimide. These results substantiate our earlier conclusion that oxygen atoms are the principal active species in the etching of organic films with the atmospheric-pressure plasma. ${ }^{10}$

\section{Conclusions}

The concentration of ground-state $\mathrm{O}$ atoms, metastable oxygen molecules, $\mathrm{a}^{1} \Delta_{\mathrm{g}}$ and $\mathrm{b}^{1} \Sigma_{\mathrm{g}}{ }^{+}$, and ozone in the downstream region of an atmospheric-pressure oxygen and helium discharge has been determined by a combination of optical spectroscopy and numerical modeling of the reaction kinetics. The dependence of the concentrations of the reactive intermediate, $\mathrm{O}\left({ }^{3} \mathrm{P}\right), \mathrm{O}_{2}$ $\left(\mathrm{a}^{1} \Delta_{\mathrm{g}}\right), \mathrm{O}_{2}\left(\mathrm{~b}^{1} \Sigma_{\mathrm{g}}{ }^{+}\right)$, and $\mathrm{O}_{3}$, on the $\mathrm{RF}$ power and oxygen partial pressure has been determined. Oxygen atoms are found to be the principal active species responsible for etching organic thin films.
Acknowledgment. This research was partially supported by a grant from Beta Squared, the UC SMART program, and the National Science Foundation, Division of Chemical and Thermal Systems. In addition, the work was conducted under the auspices of the U.S. Department of Energy, supported in part by funds provided by the University of California, and in part by funds provided by Basic Energy Sciences, Environmental Management Sciences Program, and the Office of Science and Risk Policy (award no. DE-F5607-96ER45621).

\section{References and Notes}

(1) Hartney, M. A.; Hess, D. W.; Soane, D. S. J. Vac. Sci. Technol. B 1989, $7,1$.

(2) Lieberman, M. A.; Lichtenberg, A. J. Principles of Plasma Discharges and Materials Processing; John Wiley \& Sons: New York, 1994; p 324.

(3) Grill, A. Cold Plasma in Materials Fabrication from Fundamentals to Applications; IEEE Press: New York, 1994.

(4) Brake, M.; Hinkle, J.; Asmussen, J.; Hawley, M.; Kerber, R. Plasma Chemistry and Plasma Processing 1983, 3, 63.

(5) Noxon, J. F. Can. J. Phys. 1961, 39, 1110.

(6) Borrel, P.; Richards, D. S. J. Chem. Soc., Faraday Trans. 21989, 85,1401 .

(7) Kruger, D. H.; Owano, T. G.; Laux, C. O. IEEE Trans. Plasma Sci. 1997, 25, 1042.

(8) Braun, A. E. Semicond. Int. 1999, 22, 64

(9) Jeong, J. Y; Babayan, S. E.; Tu, V. J.; Park, J.; Henins, I.; Velarde J.; Hicks, R. F.; Selwyn, G. S. Plasma Sources Sci. Technol. 1998, 7, 282. (10) Jeong, J. Y.; Babayan, S. E.; Schuetze, A.; Tu, V. J.; Park, J.; Henins, I.; Selwyn, G. S.; Hicks, R. F. J. Vac. Sci. Technol. A 1999, 17 2581 .

(11) Babayan, S. E.; Jeong, J. Y.; Tu, V. J.; Park, J.; Hicks, R. F.; Selwyn, G. S. Plasma Sources Sci. Technol. 1998, 7, 286.

(12) Schütze, A.; Jeong, J. Y.; Babayan, S. E.; Park, J.; Selwyn, G. S.; Hicks, R. F. IEEE Trans. Plasma Sci. 1998, 26, 1685.

(13) Inn, E. C. Y.; Tanaka, Y. J. J. Opt. Soc. Am. 1953, 43, 870.

(14) Vigroux, E. Ann. Phys. 1953, 8, 709.

(15) Ny, T. Z.; Choong, S. P. Chin. J. Phys. 1933, 1, 38.

(16) Krupenie, P. H. J. Phys. Chem. Ref. Data 1972, 1, 423.

(17) Pearse, R. W. B.; Gaydon, A. G. The Identification of Molecular Spectra; Wiley: New York, 1976.

(18) Gallagher, J.; Beaty, E.; Dutton, J.; Pitchford, L. J. Phys. Chem. Ref. Data 1983, 12, 109.

(19) Biondi, M. A. Principles of Laser Plasmas; Bekefi, G., Ed.; Wiley: New York, 1976; Chapter 4.

(20) Bortner, M. H.; Bauer, T. Defense Nuclear Agency Reaction Rate Handbook, 2nd ed.; DASIAC: Santa Barbara, CA, 1972.

(21) Davidson, J. A.; Sadowski, C. M.; Schiff, H. I. J. Chem. Phys. 1976, 64, 57

(22) Smirnov, B. M. Excited atoms; Energotomizdat: Moscow, 1982.

(23) Hampson, R. F.; Garvin, D. Reaction Rate and Photochemical Data for Atmospheric Chemistry-1977, NBS Special Publication 513; U.S. Government Printing Office: Washington, DC, 1978.

(24) Sabadil, H.; Bachmann, P.; Kastelewicz, H. Beitr. Plasmaphys. 1980, 20, 283.

(25) Frimer, A. Singlet $\mathrm{O}_{2}$, Vol. I, Physical-Chemical Aspects; CRC Press: Boca Raton, FL, 1985.

(26) Eliasson, B.; Kogelschatz, U. Basic Data for Modeling of Electrical Discharges in Gases: Oxygen; Asea Brown Boveri: Baden, Switzerland, 1986.

(27) Heicklen, J. Atmospheric Chemistry; Academic Press: New York, 1976.

(28) Cohen, N.; Westerberg, K. J. Phys. Chem. Ref. Data 1983, 12, 531.

(29) Baulch, D.; Cox, R.; Crutzen, P.; Hampson, R.; Kerr, J.; Troe, J.; Watson, R. J. Phys. Chem. Ref. Data 1982, 11, 327.

(30) Shibata, M.; Nakano, N.; Makabe, T. J. Appl. Phys. 1995, 77, 6181 . 